\title{
DEMOGRAPHIC AND DWELLING MODELS BY ARTIFICIAL INTELLIGENCE: URBAN RENEWAL OPPORTUNITIES IN SPANISH COAST
}

\author{
FRANCISCO JAVIER ABARCA-ALVAREZ, FRANCISCO SERGIO CAMPOS-SANCHEZ \& \\ RAFAEL REINOSO-BELLIDO \\ Department of Urban and Spatial Planning, University of Granada, Spain.
}

\begin{abstract}
The Spanish Mediterranean coast has undergone intense urban development in recent decades. It has often focused on building a property patrimony based more on real estate, business expectations and consuming resources than on its actual use. Similarly, its functionality and need to adapt to social needs and the requirements of the certain demographic profiles of its time have largely been ignored. The purpose of this study is to shed light on the Spanish Mediterranean coast's existing residential models and the relationship with the local demographic reality of users. Its aim is to be part of a Decision Support System which focuses on urban regeneration and functional recovery. This study uses heuristic methodologies to demonstrate the coherence of an abundance of open access data. Such methodologies do not necessarily require specific hypotheses or formulations to generate useful knowledge. The 2011 Population and Housing Census (INE) is used as a knowledge source, on which data mining techniques based on Artificial Intelligence techniques are applied. We specifically use Self-Organising Maps (SOM) through Artificial Neural Networks (ANN), subsequently mapping the results through a Geographic Information System (GIS). These techniques permit an exploration of the different residential profiles in this territory. Each profile exposes very different levels of sustainability and resilience, identifying the groups or social collectives that singularly inhabit them, which are at times authentic drivers of the maintenance and growth of these models. To the extent that they are linked to demographic profiles, the knowledge obtained in this study is evidence of the different residential profiles' territorial location, and highlights the opportunities and weaknesses of urban regeneration.

Keywords: Artificial Neural Network (ANN), Coastal Areas, Decision Support System (DSS), Dwelling, Geographic Information System (GIS), Self-Organising Maps (SOM), Urban Renewal
\end{abstract}

\section{INTRODUCTION}

The Euro-Mediterranean coast can be described as a quintessential artificial landscape, transformed by anthropic activities over several millennia and whose biodiversity is also determined by man [1]. Territorial transformations begin to intensify during the second half of the 20th century, with an increase in maritime trade and capitalist development, initially driven by a modernisation of ports and railways, and subsequently by the control of the growth of such cities [2]. Urbanisation was especially intense from the mid-twentieth century onwards, leading to an enormous transformation of Spanish, French and Italian coastal landscapes [3]. In these territories, the scaling down of agricultural activity has occurred simultaneous to consequent rural emptying and 'coastalisation': the progressive concentration of the population and its activity in territories close to the coastline [4]. The peculiar circumstances that underpinned the start of the coastal occupation, characterised by that period's property development enthusiasm and an almost total absence of planning, resulted in a rapid increase in the population living in Spanish Mediterranean coastal provinces, which ranged between $35 \%$ and $80 \%$ during the years 1950-1981, and between $25 \%$ and $40 \%$ in the years 1981-2005 (source INE). These realities are in addition to a complex Spanish governmental context, in which competences of the autonomous communities' governments in Urban Planning and Environment overlapped with those of state government in coastal 
development, such as with Law 2/2013 on the Protection and Sustainable Use of the Coast, and Royal Decree 876/2014 by which the General Coasts Regulation was approved.

Doubts are arising regarding the sustainability, resilience and viability of the extensive conurbation the Spanish coastline is becoming. A second discussion stemming from this conurbation process follows on from the ongoing debate regarding what is urban and what is not. References to this city-countryside dialectic can be found in theoretical studies [5] and experimental research, which emphasise protected environments as key to the conservation of nature and the urbanisation processes [6]. Other investigations focus on the central role that can potentially be played by locations that lie between the countryside and the city [7] and even their interpretation with emerging technologies [8].

Today we can no longer ignore certain fields of knowledge that were historically isolated. Sociology and human geography are connected to planning and land use, and vice versa. The migratory phenomenon of the end of the 20th century was a significant change for Spain, which went from being a country of emigrants, to one that received them itself; mainly foreign workers from Latin America and North Africa-also on their way to northern Europe - as well as immigrants from the European Union, of a more affluent profile, such as retired people [9].

Currently, tourist immigration from the north and west of Europe is generating complex social network systems; differentiating between the immigrant who is active in the labour market and that who is not is difficult and confusing, according to Josefina Domínguez Mujica and Juan Manuel Parreño Castellano [10], who also state that a good number of those immigrants, approximately 130,000 in 2009 , who come mainly from the United Kingdomalthough also Sweden, Finland, Denmark, Ireland, the Netherlands, Belgium, Luxembourg, France, Switzerland, Austria and Greece — and who have played an active role in the labour market, also end up retiring in Spain and thus become tourist immigrants. These are labour migrants who eventually become retired tourist immigrants; this phenomenon especially occurs in certain territories of Andalusia, specifically the Costa del Sol in Malaga [10]. These territories have been extensively transformed by these communities through an occupation process and a kind of metabolisation of traditional activities for new ones which, supported by global and universal trade, have facilitated the movement of goods from other geographical areas and resulted in a decrease of local production which was fundamentally focused on agriculture. The development of mass tourism, especially along the coast, generates demands for infrastructure and employment, while also exerting intense pressure on the environment, population and society which can lead to a deterioration of the quality of life, made clear in the study led by Chrysostomos Italos [11] which investigated the influence of Mediterranean tourism on the occupation of Cypriot land.

The environment can be seen from different and even contrary perspectives [12] by each person, it can be exploited in many different ways. Certain authors describe how the use and perception of the environment is changing in certain territories. Dwight Hines [13] describes the rural gentrification of Montana (USA) caused by immigration, in the form of permanent tourism, by studying a group of relatively young post-industrial urbanites. According to him [13] the area passed from an industrial landscape where production and consumption of services was prioritised, to one that valued the production and consumption of experiences, and is used as an example of late modern tourism. These permanent tourists undertake cultural projects by inserting themselves into a physical and social landscape, while socially organising themselves into relevant groups in regard to administrative institutions. The immigrant tourist of the 21 st century seems to colonise territories in a unique manner whose method and 
resulting interactions with the urban environment and the existing societies in which they establish themselves are perhaps still unknown. In a complex context in which development models focused on urban capital gains - which ignore the generation of residences that are barely used and often left empty_overlap with other emerging models that operate according to the territories' material and immaterial values, such as a support for a lifestyle that is linked to native culture and environment, analysing and reviewing the prevailing residential models of these territories and connecting them with the social and demographic strata that occupy them is of importance.

The main objective of this research study is to provide useful knowledge which can be used to make informed decisions about the existing residential models on the Spanish Mediterranean coast (Fig. 1) and try to shed light on their relationship with, whenever these exist, their local demographic reality. The main knowledge source used is the 2011 Population and Housing Census (INE), on which we apply data mining techniques using Artificial Intelligence and GIS mapping applications. These techniques will highlight the different residential profiles within this vast territory, each of them with very diverse levels of sustainability and resilience, identifying the groups or social collectives that predominantly inhabit them, which are at times authentic drivers of the maintenance and growth of the development models that singularly colonise the coastal territories. The knowledge obtained in this study will be evidence of the different residential profiles' territorial location, forming part of a Decision

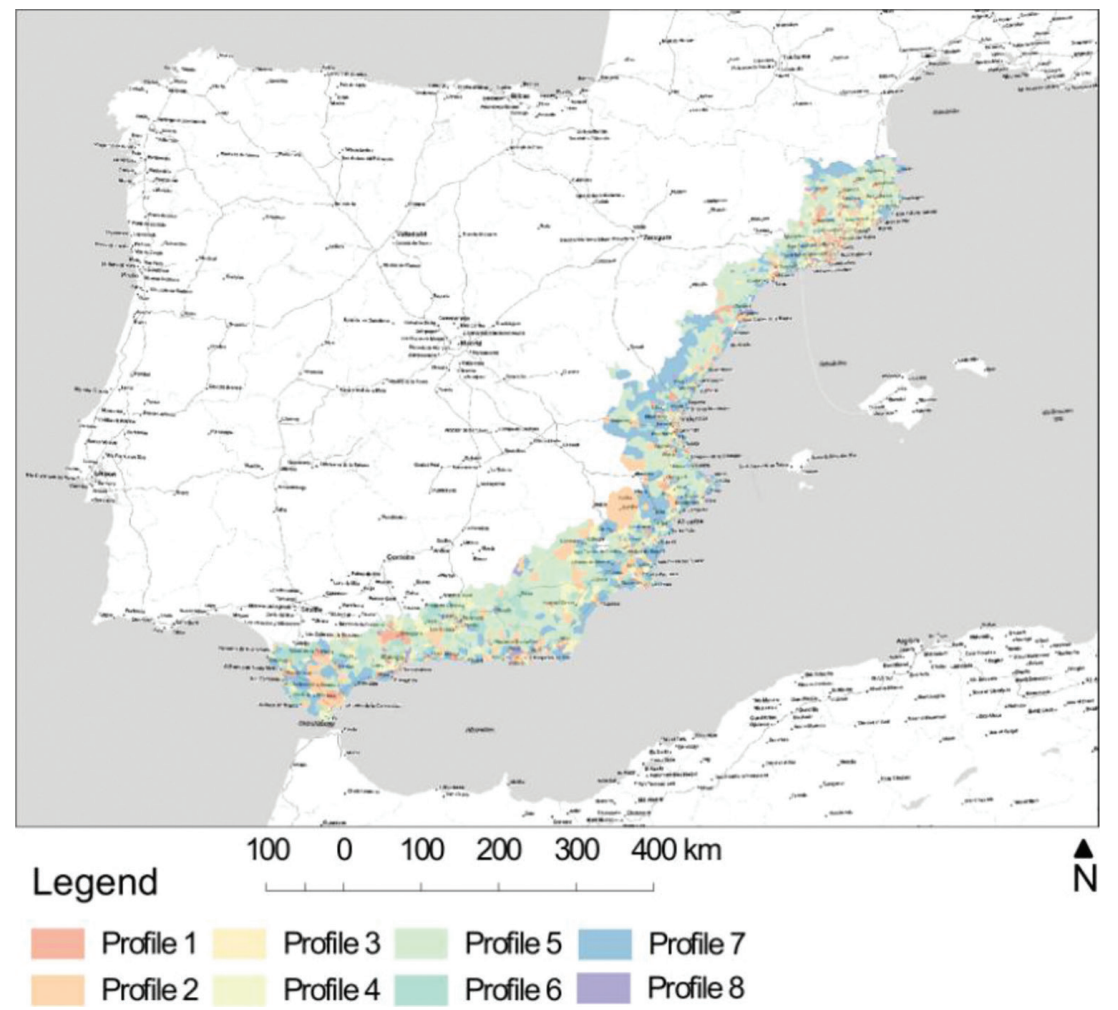

Figure 1: Location of the case study area. The results of soil classification carried out by SOM techniques are represented. Source: Author's own. 
Support System (DSS) in that it will identify opportunities and weaknesses of urban regeneration linked to demographic profiles that are potentially in continuous transformation.

\section{METHODOLOGY AND RESULTS}

The methodology used was chosen because it could be part of a Decision Support System in which the analysis of spatial and territorial implications is singularly relevant. DSSes are effective instruments or 'vehicles' for the incorporation and integration of complex realities and problems and to support certain decisions: the perfect definition of what is developed and why it has traditionally been deemed crucial [14], as has avoiding, insofar as possible, any improvisation and imprecision and an emphasis on paying special attention to the flexibility and resilience of the system itself. Recently, the emergence of new techniques such as Machine Learning and others that are not as new such as Artificial Neural Networks, has slightly changed the paradigm of DSSes, and they are currently considered to be useful for the understanding of reality, detecting problems in that reality and for formulating new hypotheses - not only as an instrument to verify the previously established one. On this basis of new approaches, five types of DSS have been categorised [15]: (i) communication oriented; (ii) data oriented; (iii) document oriented; (iv) knowledge oriented, and (v) model oriented. Our research focuses on the fourth type, knowledge oriented, constructing DDS models for this that can verify and interpret the research.

For optimal methodological understanding, and in order to obtain the best results possible from the DSS, the phases defined by Mark S. Silver [16] are followed: (i) processing information and functions, (ii) data sets, (iii) models, and (iv) visual representations.

\subsection{Processing information and functions}

The information used for the research study was sourced entirely from the open-access 2011 Spanish Population Census by the National Institute of Statistics (INE). Once this information was collected, we carried out an intense data preparation consisting fundamentally of the integration and filtering of it and transforming attributes through the creation of aggregate indicators, which had the peculiarity of objectively and concisely summarising the main demographic and residential qualities in a much better manner than the original. For this, most of the original indicators based on absolute frequencies were transformed into relative frequencies or ratios. Likewise, new indicators were also created as synthetic aggregators from other original indicators. Such indicators are named specifically by adding the letter ' $\mathrm{f}$ ' as a suffix when they are synthetic, or ' $x$ ' when new. Instances: The unit of territory on which the data were obtained was the census section, reaching all of the 12,307 census sections of all the provinces along the Spanish Mediterranean, while the study included the totality of the surface area and population registered in the provinces of Cádiz, Málaga, Granada, Almería, Murcia, Alicante, Valencia, Castellón, Tarragona, Barcelona and Girona. Therefore, no sampling was done, and the study data treated included the entire population and residence in the census.

Attributes: The attributes used for the modelling phase, 87 variables, comprised 24 variables in their residential dimension, such as intensity of use (11 variables), connection or personal affiliation with the property (eight variables), size of the dwelling (four variables) and a general variable. Also during the modelling phase, profiles were created from these data and compared with 63 demographic attributes of its residents. These included 3 general character, 3 age, 8 origin, 24 nationality, 5 civil status and 20 educational indicators. 


\subsection{Data sets}

We initially used two databases with information on each and every one of the census sections under study: the one that was used in the modelling phase fell within the residential dimension described above, and the other contained demographic information of the residents themselves. The management of these databases was fundamentally independent, connecting only after modelling to verify how the demographic dimension fits the residential profiles obtained.

\subsection{Models}

It is a classification and knowledge model. The objectives for this model include, firstly, the classification and labelling of the census sections by integrating the study's residential data. An artificial neural network was used during this phase, specifically Self-Organising Maps (SOM). The SOM were initially proposed by Teuvo Kohonen [17, 18]. It is a knowledge discovery or data mining technique using an Artificial Neural Network (ANN). It is created with Artificial Intelligence, and has been effectively used in many disciplines as it visualises and displays the information clearly and orderly, classifying and labelling the subjects into classes, without the need for prior labelling or training, such that it is considered an unsupervised learning neural network. These programs are considered capable of reducing the complexity of a huge amount of data [19] and are often used for this purpose, to classify [20], and to label entities [21]. They have very notable advantages: compared with other dimensional reduction methods, such as PCA (Principal Component Analysis) or MDS (Multidimensional Scaling), SOM preserve the topology of the data with a more efficient use of the space available in the map representation [22]; they are relatively insensitive to missing values and tolerate non-normal distributions of data [23], and they are more robust than K-means.

The grouping, clustering and classification of the subjects is done through an additional Ward-cluster analysis on the map. Profiles or prototypes are generated by modelling patterns and trends in information [24]. The choice of the number of resulting profiles depends on the researcher and their interpretation. We decided that a total of eight profiles was sufficient for our study, integrating information that was understandable and statistically accurate. To facilitate the collection of knowledge on the profiles obtained, each profile was characterised with the mean, standard deviation, maximum and minimum [25], with the objective of mainly two additional results, (i) the factor or variable that is more important for the effect and (ii) the value of such a factor [26]. For the analysis of the profiles as well as the statistical information that defined them, the mono-variable SOM maps were valuable (Fig. 2).

To complete the modelling, the demographic information for residents of each census section was integrated into the residential profiles, comparing the statistical significance of such belonging in relation to globality. To comply with recommendations by the American Statistical Association [27], for each variable and profile-in addition to the statistical significance by means of the bilateral Student's t-test (p-value 0.05) — the effect size was calculated, understood as the ratio of the difference of the mean between the experimental group (profile) and that of the control group (population mean) divided by the population standard deviation [28]. The Effect Size (ES) for each attribute/variable party to the profile's construction is studied: positive: +++ ES large, ++ ES medium, + ES small; negative: - ES low, - - ES medium, - - ES large [29], obtaining very relevant information on the effect each variable 

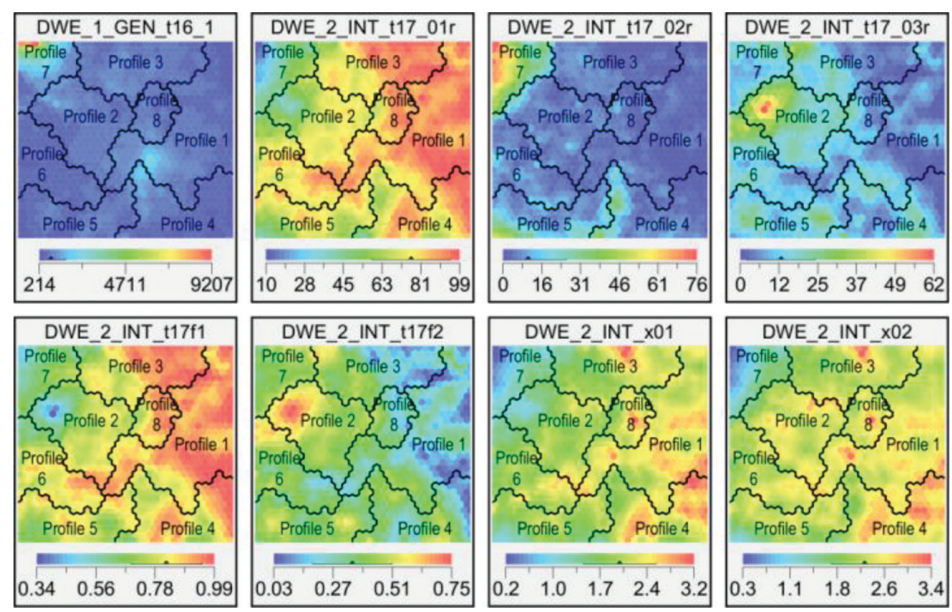

Figure 2: Extract of the set of self-organised monothematic maps for the classification of eight profiles. Dwelling variables. Source: Author's own.

has on the definition and singularity of each profile. The following can be concluded for each profile from an analysis of the p-value and the ES:

\subsubsection{Profile 1:}

The first residential dimension model is characterised by a significant presence of main dwellings, mostly purchased with pending payments; a high number of people per household, and a surface area per house and number of rooms lower than the average. By comparing the residential model with demographic information, we can see that this profile's population is mostly younger than average. It is thus a densely occupied city model, used mainly as a main dwelling, of small size and with a young population. It probably does not offer adequate opportunities for family units who require larger spaces.

\subsubsection{Profile 2:}

This residential dimension is associated with a significant presence of empty homes; a low number of people per household, and a significant presence of owner-occupied homes owned through inheritance-donation or transferred free or at low prices. Noteworthy of this demographic dimension is a significant presence of people of foreign nationality and born in Africa. It is therefore an urban model whose main problem or difficulty is a shortage of residents.

\subsubsection{Profile 3:}

As a summary, this is a residential rental profile with few people per dwelling; a significant presence of people of foreign origin, probably already settled through many years of employment; a relatively high education level, and that has a certain reluctance to get married. It should be noted that this resident profile may have displaced other indigenous residents and might have been relegated to functional obsolescence caused by the proliferation of small houses with few opportunities for larger families. 


\subsubsection{Profile 4:}

The residence in this profile is usually a main dwelling; has a high number of people per dwelling; owner-occupied, where it has been purchased in full or has pending payments and often has a greater surface area and number of rooms than the average. At a demographic level, this housing profile has a young population, especially in regard to females; its nationality is eminently of Spanish origin; is mainly married, and its education level is slightly higher than the average. We can conclude that this residential profile-larger than the previous one-is mainly occupied by Spanish families.

\subsubsection{Profile 5:}

This residential dimension shows a predominance of owner-occupied housing obtained by inheritance or donation and to a lesser extent obtained transferred free or at low prices; predominance of secondary or empty dwellings; reduced presence of persons per dwelling and has a large surface area and large number of bedrooms. Regarding its demographic dimension, this residential profile is occupied by a relatively elderly population; of a generally Spanish nationality; usually married and very few single people, and has a noticeably lower education level than the other profiles. As a synthesis, this profile is continuous between generations, the residence is of a large size and sometimes becomes a second residence or obsolete and empty.

\subsubsection{Profile 6:}

In this profile, there is a high number of empty dwellings; a very small number of people per household, and houses are often obtained by inheritance or donation. The demographics of the population of this residential profile is of an elderly age; a significant presence of people born in Africa, Central and South America and the Caribbean; a large number of widowers; elderly single people, and a high presence of illiterate people who do not have even a basic level of education. In this profile, empty residences are frequently seen and their obsolescence is intuited, although dwellings are sometimes occupied by immigrants from Africa and Central America, the population has a low educational level, is ageing and live alone.

\subsubsection{Profile 7:}

In this residential profile, the houses are eminently secondary, with very few people living in each house, which have usually been bought and are almost always fully paid, and have fewer rooms than the average. Regarding its demographic dimension, this profile presents a greater number of men than women; with a higher than average age; a predominance of people born in another EU member state, although there is a presence of people born in non-EU European countries; includes few single people but many widowers, and its population frequently has secondary school studies, although those aged over 64 have a higher than average education level. It is an eminently semi-permanent tourist area, with people who take long stays there over summer or live there permanently.

\subsubsection{Profile 8:}

From a residential dimension perspective, which builds the profile itself, this profile comprises of main dwellings; many people per household; a reduced number of dwellings per home; each house has frequently been given to its proprietor completely free or at low prices, and there is no special significance in regard to the size of the houses.

At the demographic level, the dwellings are occupied by young residents, who are frequently single, and whose education level is scarcely higher than average. In this profile, neighbourhoods are eminently made up of social or public housing. 


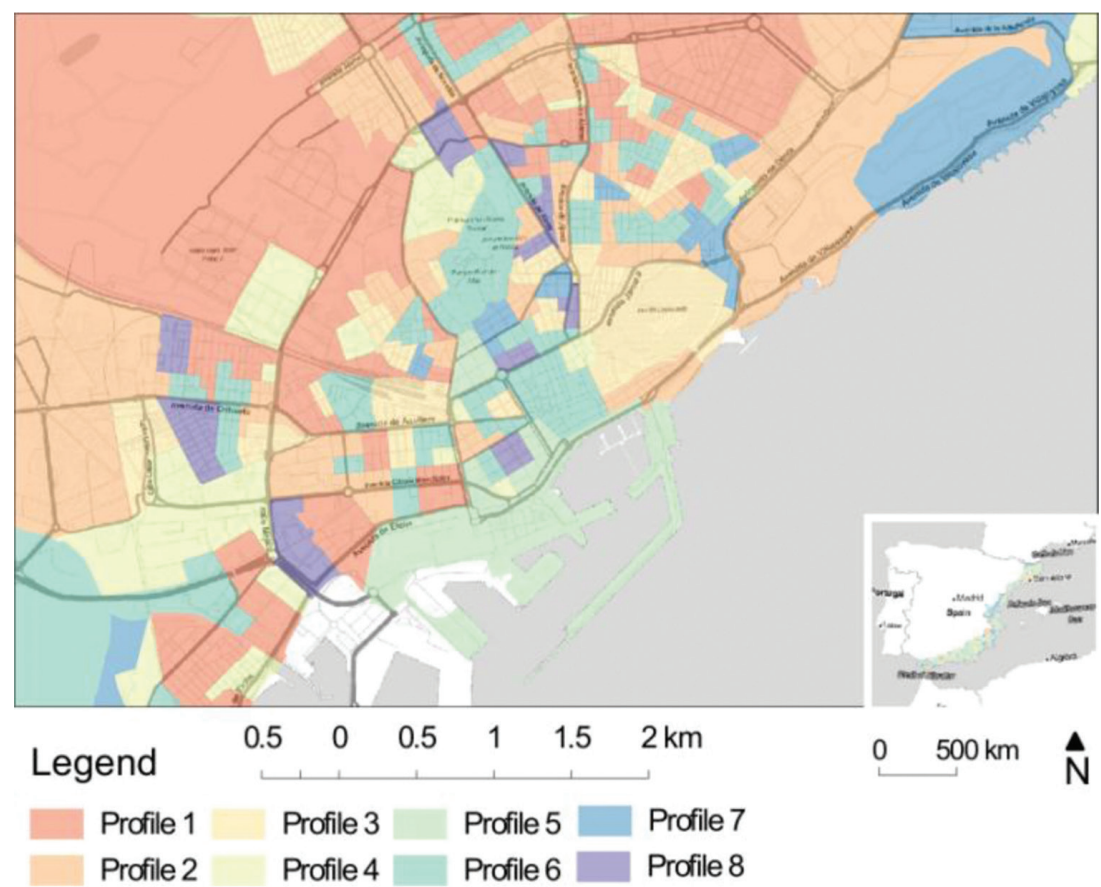

Figure 3: GIS representation of the SOM classification of the eight profiles in the area of Alicante. Source: Author's own.

\subsection{Visual representations}

One of the qualities presented by the SOM cartographies is the ability to display the resulting information so that it is relatively easy to understand, by showing a two-dimensional representation of the starting instances, with the notable characteristic that each instance's 'neighbour' is the instance that has the most similar qualities to it. These maps contribute to understanding the distribution of the data in the SOM map. Finally, as each evaluated instance has their own identity and shape in the space, the profiles determined in modelling phase 1 will be represented by a GIS (Fig. 3). Returning the instances to GIS once classified into classes is frequent, for example, in the representation of the SOM clustering results on the ecological risk of contamination [25] or applying them experimentally to data sources from the Lisbon Metropolitan Area socio-demographic information [30, 31].

By representing the eight profiles in the territory using GIS, the consistency of the results obtained through SOM modelling can be verified. Likewise, it is possible to compliment knowledge through spatial interpretation, identifying the opportunities and weaknesses of the distribution of such profiles throughout the urban and territorial environments.

\section{DISCUSSION}

The methodology used, based on a SOM analysis, has facilitated the efficient analysis of complex geographic data sets [32] sourced from an open-access population census, allowing an exploratory analysis to be performed with these data [19] where more than $1,000,000$ 
unique data have been processed. Included in this information are variables of a very diverse nature, ranging from the residential to the demographic. Its use has ensured traditional descriptive classifications are more powerful, robust and complete [20] and facilitated the understanding of spatial distribution patterns [25] that occur along the coast under study, allowing us to visually explore, validate and evaluate $[33,34]$ the existence of differentiated 'regions' along the coast studied. Thus, we can clearly define coastal territories with a notable influence of residential models aimed at European tourists, profile 7, who purchase homes in places that range from tourist developments similar to resorts on the coast to interior locations with unique landscapes and surroundings (for example, the Alpujarra region of Granada or the mountainous area of the Pueblos Blancos in Cadiz).

Thanks to the consistent geometrical properties of the SOM results, the resulting classifications can be coded into a GIS, making them even more accessible and understandable to an audience not familiar with SOM [35], thus allowing the researcher to concentrate on the interpretation of the results, more than on the statistical calculations that legitimise them. In this way, spatial considerations can be inferred from the taxonometric groups found [25,36], overcoming the traditional challenges associated with the study of the complexity of environmental communities, thus evidencing the enormous potential of using SOM and GIS in combination [37]. The implemented tool constitutes a powerful alternative solution at a time that is characterised by information technologies and by the proliferation of data [38], and it can be used as a Decision Support System to analyse and visualise sets of statistical indicators for various applications [39]. Relevant information can be obtained through this technological combination, differing according to the moment and the decision-maker in question which requires that knowledge. In the knowledge obtained we can see information has been approached from several different angles: the data was processed with strategic territorial knowledge, for example, in the recognition that profile 5, based on inheritance from generation to generation, has significant weight in territories such as Hoyas de Guadix and Baza in the province of Granada or in the Tarragona region of the river Ebro. Another level of granularity can be found when we focus on the local or municipal level, for example we can see the weight of profile 3, at the centre of Barcelona, which unveils residential values that revolve around reduced typologies, and with a very international or cosmopolitan human profile. Certain gentrification vectors are observed, where the original residential fabric has been displaced to other more peripheral areas, opening up opportunities for real estate rental and tourism businesses.

Conversely, we must bear in mind certain precautions and limitations in the use of these methodologies: (i) an analysis of the population from a census section is not a complete analysis of the population and extreme caution must be exercised; we must limit the inference to an observation that does not touch individuals [19]; (ii) the complete integration between SOM and GIS is complex [22]; (iii) there is a significant technological gap between planning and these technologies [40]; and (iv) the combination of expert knowledge with SOM results requires some creativity [35], as the results are not as immediately obvious as would be desirable.

\section{CONCLUSION}

Through research applied to the case study of the Spanish peninsular Mediterranean, we have shown that these tools are useful for describing complex and relevant demographic phenomena based on a residential reality. The methodologies used in the research have allowed us to show different residential profiles in our case study, each of them being linked to a specific 
demographic reality. Profiles with notable singularities have been found, with different levels of sustainability and resilience, ranging from profiles with an emerging gentrification, to profiles with serious problems due to the emptying of their residence, others with a scarcity of housing for families or clearly tourist areas and with samples of social exclusion.

Given the strategic relevance for urban regeneration of such discoveries, policies and urban design and planning should (i) consider such evidence and understand the appropriateness of using methodologies, such as those we have discussed, in understanding realities that are themselves complex, and as has been shown (ii) bear in mind the connection between the residential and demographic dimensions of such strategies.

We can therefore conclude that there is a connection and relationship between the residential configuration and the demographic phenomena in the coastal territory studied, and that caution must be taken to avoid establishing a cause-effect between such phenomena, which would require other investigations that were not included in this study's objectives.

\section{ACKNOWLEDGEMENTS}

This research study has been partially co-funded by the Research Programme of the University of Granada's 2016 (Regional Government of Andalusia) own Research Plan 'Precompetitive Research Projects' (PP2016-PIP09).

\section{REFERENCES}

[1] Salizzoni, E., Protected Areas confronted by urbanization processes: challenges and operative perspectives. Protected Areas in Europe Challenging Regional and Global Change, eds. T. Hammer, I. Mose, D. Siegrist \& N. Weixlbaumer, Oekom, Munich, pp. 47-58, 2016, available at http://porto.polito.it/id/eprint/2671217

[2] Gómez-Ordóñez, J.L. \& Martínez-Hidalgo, C., The growth of the Mediterranean port cities between 1850 and 1950. Conference Importance of Place-Conference Proceedings Sarajevo. Sarajevo, pp. 597-617, 2015.

[3] Salizzoni, E., Paesaggi Protetti. Laboratori di sperimentazione per il paesaggio costiero euro-mediterrano, Firenze University Press: Firenze, 2012.

[4] Leontidou, L. \& Tourkomenis, K., El turismo residencial y la litoralización del Mediterráneo: la migración del norte a las costas meridionales de Europa. Turismo, urbanización y estilos de vida: las nuevas formas de movilidad residencial, eds. T. Mazón, R. Huete \& A. Mantecón. Murcia, pp. 37-54, 2009.

[5] Abarca-Alvarez, F.J. \& Campos-Sanchez, F.S., El paisaje desde el límite de lo urbano: una utopía necesaria y educadora. Urban NS, 5, pp. 63-78, 2013, available at https:// dialnet.unirioja.es/descarga/articulo/4974963.pdf

[6] Salizzoni, E., Conserving biological and cultural diversity along the Latin Arc: The role of Protected Areas. Biocultural diversity in Europe, eds. M. Agnoletti, F. Emanueli, Springer: Dordrecht, pp. 471-85, 2016.

[7] Pérez-Campaña, R., Abarca-Alvarez, F.J. \& Talavera-Garcia, R., Centralities in the city border: a method to identify strategic urban-rural interventions. Ri-Vista, 2, pp. 38-53, 2016. Available at http://www.fupress.net/index.php/ri-vista/article/view/19370

[8] Abarca-Alvarez, F.J., Pérez-Campaña, R. \& Talavera-Garcia, R., Identificación de patrones espaciales del borde urbano mediante mapas auto-organizados de la centralidad de la red viaria. Revista Urbano, 36, pp. 18-29, 2017.

[9] Ortega Pérez, N., España: Hacia una nueva política migratoria. Universidad de Granada: Granada, 2003. 
[10] Dominguez Mujica, J. \& Parreno Castellano J.M., Workers and retirees. The flexible condition of Northern and Western European migrants in Spanish tourist destinations. Boletín de la Asociación Geográficos Españoles, 64, pp. 419-421, 2014.

[11] Italos, C., Akylas, E. \& Hadjimitsis, D.G., Effects of tourism and globalization on land cover and the influence on the quality of life of Paphos area in Cyprus. Proceedings of the SPIE, eds. D.G. Hadjimitsis, K. Themistocleous, S. Michaelides \& G. Papadavid Papadavid(92290Q), p. 8 2014, available at http://proceedings.spiedigitallibrary.org/ proceeding.aspx?doi=10.1117/12.2069967

[12] Rapoport, A., Aspectos humanos de la forma urbana. Hacia una confrontación de las ciencias sociales con el diseño de la forma urbana. Gustavo Gili: Barcelona, 381 pp., 1978.

[13] Hines, J.D., Rural gentrification as permanent tourism: the creation of the 'New' West archipelago as postindustrial cultural space. Environment and Planning D: Society and Space, 28(3) pp. 509-525, 2010.

https://doi.org/10.1068/d3309

[14] Keen, P.G.W., Decision support systems: the next decade. Decision Support Systems, 3(3), pp. 253-265, 1987. https://doi.org/10.1016/0167-9236(87)90180-1

[15] Power, D.J., Sharda, R. \& Burstein, F., Decision support systems. Wiley Encyclopedia of Management. Ed. C.L. Cooper, John Wiley \& Sons: Chichester, UK, pp. 1-4, 2015.

[16] Silver, M.S., On the design features of decision support systems: The role of system restrictiveness and decisional guidance. Handbook on Decision Support Systems 2: Variations. eds. F.W. Burstein \& C. Holsapple. Springer-Verlag: Berlin Heidelberg, pp. 261-91, 2008.

[17] Ritter, H. \& Kohonen, T., Self-organizing semantic maps. Biological Cybernetics, 61(4), pp. 241-254, 1989.

https://doi.org/10.1007/bf00203171

[18] Kohonen, T., The self-organizing map. Neurocomputing, 21(1-3), pp. 1-6, 1998. https://doi.org/10.1007/bf00203171

[19] Spielman, S.E. \& Thill, J.C., Social area analysis, data mining, and GIS. Computers, Environment and Urban Systems, 32(2), pp. 110-122, 2008.

https://doi.org/10.1016/j.compenvurbsys.2007.11.004

[20] Hamaina, R., Leduc, T. \& Moreau, G., Towards urban fabrics characterization based on buildings footprints. Bridging the Geographic Information Sciences, ed. J. Gensel, pp. 231-248, 2012. http://dx.doi.org/10.1007/978-3-642-29063-3_13

[21] Salah, M., Trinder, J. \& Shaker, A., Evaluation of the self-organizing map classifier for building detection from lidar data and multispectral aerial images. Journal of Spatial Science, 54(2), pp. 15-34, 2009.

https://doi.org/10.1080/14498596.2009.9635176

[22] Agarwal, P. \& Skupin, A., Self-organising Maps: Applications in Geographic Information Science. Wiley, pp. 2008, 2015.

[23] Zhang, J., Shi, H. \& Zhang, Y., Self-organizing map methodology and google maps services for geographical epidemiology mapping. DICTA 2009 - Digital Image Computing: Techniques and Applications, pp. 229-235, 2009.

https://doi.org/10.1109/dicta.2009.46 
[24] Weiss, S.M. \& Indurkhya, N. Predictive Data Mining: A Practical Guide, Morgan Kaufmann, San Francisco, 1998.

[25] Faggiano, L., de Zwart, D., García-Berthou, E., Lek, S. \& Gevrey, M. Patterning ecological risk of pesticide contamination at the river basin scale. Science of The Total Environment, 408(11), pp. 2319-2326, 2010.

http://dx.doi.org/10.1016/j.scitotenv.2010.02.002

[26] Wu, P.K. \& Hsiao, T.C., Factor knowledge mining using the techniques of AI neural networks and self-organizing map. International Journal of Distributed Sensor Networks, 2015, pp. 1-19, 2015. https://doi.org/10.1155/2015/412418

[27] Wasserstein, R.L. \& Lazar, N.A., The ASA's statement on p-values: context, process, and purpose. The American Statistician, 70(2), pp. 129-133, 2016. https://doi.org/10.1080/00031305.2016.1154108

[28] Coe, R. \& Merino, C., Magnitud del efecto: Una guía para investigadores y usuarios. Revista de Psicología, 21(1), pp. 147-177, 2003.

[29] Cohen, J., Statistical Power Analysis for the Behavioral Sciences. Lawrence Erlbaum Associates, Publishers, 590 pp, 1998.

[30] Bação, F., Lobo, V. \& Painho, M. The self-organizing map and it's variants as tools for geodemographical data analysis: the case of Lisbon's Metropolitan Area. Computers \& Geosciences, 31, pp. 155-63, 1995.

https://doi.org/10.1016/j.cageo.2004.06.013

[31] Bação, F., Lobo, V. \& Painho, M., Self-organizing maps as substitutes for k-means clustering. Computer Science, 3516, pp. 476-483, 2005.

https://doi.org/10.1007/11428862_65

[32] Takatsuka, M., An application of the Self-Organizing Map and interactive 3-D visualization to geospatial data. Proceedings of the 6th International Conference on GeoComputation, Brisbane, pp. 24-26, 2001.

[33] Abarca-Alvarez, F.J. \& Osuna-Pérez, F. Cartografías semánticas mediante redes neuronales: los mapas auto-organizados (SOM) como representación de patrones y campos. EGA Revista Expresión Gráfica Arquitectónica, 18(22), 154-163, 2013. https://doi.org/10.4995/ega.2013.1692

[34] Yan. J. \& Thill, J.C., Visual data mining in spatial interaction analysis with self-organizing maps. Environment and Planning B: Planning and Design, 36(3), pp. 466-486, 2009.

https://doi.org/10.1068/b34019

[35] Kauko, T., Using the self-organising map to identify regularities across country-specific housing-market contexts. Environment and Planning B: Planning and Design, 32(1), pp. 89-110, 2005.

https://doi.org/10.1068/b3186

[36] Abarca-Alvarez, F.J., Campos-Sánchez, F.S. \& Osuna-Pérez, F. Taxonomía de las inmigraciones turísticas de Andalucía basada en las cualidades de sus asentamientos urbanos. In: Congreso Migraciones Contemporáneas, Territorio y Urbanismo. Cartagena, pp. 301-315, 2015.

[37] Basara, H.G. \& Yuan, M., Community health assessment using self-organizing maps and geographic information systems. International Journal of Health Geographics, 7, p. $67,2008$.

https://doi.org/10.1186/1476-072x-7-67 
[38] Hatzichristos, T., Delineation of demographic regions with GIS and computational intelligence. Environment and Planning B: Planning and Design, 31(1), pp. 39-49, 2004. https://doi.org/10.1068/b1296

[39] Kaski, S. \& Kohonen, T., Exploratory data analysis by the self-organizing map: structures of welfare and poverty in the world. Neural Networks in Financial Engineering. Proceedings of the Third International Conference on Neural Networks in the Capital Markets, pp. 498-507, 1996. Available from: http://citeseerx.ist.psu.edu/viewdoc/ summary?doi=10.1.1.53.3954

[40] Streich, B. Stadtplanung in der Wissensgesellschaft Ein Handbuch. VS Verlag für Sozialwissenschaften, 2005. 